\section{Promoção, proteção e apoio à amamentação na atenção primária à saúde no Estado do Rio de Janeiro, Brasil: uma política de saúde pública baseada em evidência}

\author{
Breastfeeding promotion, protection, \\ and support in primary health care \\ in the State of Rio de Janeiro, Brazil: \\ a case of evidence-based public health policy
}

Maria Inês Couto de Oliveira 1 Luiz Antonio Bastos Camacho ${ }^{2}$ Ivis Emília de Oliveira Souza ${ }^{3}$
1 Instituto de Saúde da Comunidade, Universidade Federal Fluminense, Niterói, Brasil. 2 Escola Nacional de Saúde Pública Sergio Arouca, Fundação Oswaldo Cruz, Rio de Janeiro, Brasil.

3 Escola de Enfermagem Anna Nery, Universidade Federal do Rio de Janeiro, Rio de Janeiro, Brasil.

Correspondência M. I. C. Oliveira Instituto de Saúde da Comunidade, Universidade Federal Fluminense. Rua Marquês do Paraná 303, Prédio Anexo, Niterói, $R J$ 24030-210, Brasil. marines@vm.uff.br

\section{Abstract}

This article evaluates a policy for breastfeeding promotion, protection, and support in primary health care units in Rio de Janeiro State, Brazil, analyzing the assumptions, interventions, and results based on a log-frame model. A systematic review sought to identify effective procedures and strategies for extending breastfeeding duration, constituting the basis for creating "Ten Steps" in the "Breastfeeding-Friendly Primary Care Initiative" launched in Rio de Janeiro State in 1999. A corresponding evaluation method was developed and applied to verify the performance of 24 primary health care units from different parts of the State. A direct association was found between the practical implementation of these steps and prevalence of exclusive breastfeeding, as well as with mothers' satisfaction. An analysis of meanings ascribed by pregnant women and mothers to the support provided for breastfeeding identified five categories: "no support", "doubtful support”, "encouragement", "guidance", and "partnership". The evaluation model allowed staff at the health care units to recognize opportunities for improving the program, in order to reverse the current low prevalence of exclusive breastfeeding.

Breast Feeding; Primary Health Care; Health Promotion

\section{Introdução}

Apesar de o desmame precoce ser uma realidade, pesquisas realizadas nos últimos trinta anos demonstram que a prática do aleitamento materno tem aumentado no Brasil. A mediana do tempo de amamentação evoluiu de 1,5 mês em 19751 para 4,1 meses em 1989 2, 6,7 meses em 19963 e 9,9 meses em 1999 4. A mesma tendência tem sido observada quanto à prevalência de aleitamento materno exclusivo, que passou de 3,6\% em 19865 para 35,6\% em 19994 entre os bebês menores de quatro meses. Esse incremento se deve em grande medida ao Programa Nacional de Incentivo ao Aleitamento Materno, criado, em 1981, pelo Ministério da Saúde (MS), conjugando ações multisetoriais, principalmente nas áreas de comunicação social, assistência à saúde e legislação 6 . Os índices alcançados, no entanto, ainda estão bem distantes das recomendações 7 da Organização Mundial da Saúde (OMS) e Fundo das Nações Unidas para a Infância (UNICEF): aleitamento materno exclusivo ${ }^{8}$ por seis meses e aleitamento materno complementado pelos alimentos da família até os dois anos ou mais.

O principal programa da área da saúde voltado para o incremento do aleitamento materno tem sido a Iniciativa Hospital Amigo da Criança 9 (IHAC), lançada pela OMS/UNICEF em 1992. A IHAC tem contribuído para aumentar a incidência e a duração da amamentação, mas 
não tem alcançado os patamares desejados. Mesmo que a cobertura desse programa se expanda, seu potencial de impacto tem limites, pois, em nosso país, apenas as gestações de risco são acompanhadas em hospitais, e a alta da maternidade costuma ocorrer no primeiro ou segundo dia de pós-parto, antes de a amamentação estar plenamente estabelecida.

No Brasil, assim como em muitos outros países, a rede de assistência primária à saúde é pública e disponível à maioria das mulheres. Constitui a principal responsável por acompanhar as gestantes durante o pré-natal e o binômio mãe-filho nos primeiros anos do bebê. A gestação é uma etapa chave para a promoção do aleitamento materno, pois é nesse período que a maioria das mulheres define os padrões de alimentação que espera praticar com seu filho 10. Após a alta da maternidade, o acompanhamento pediátrico ou de puericultura durante a primeira infância é etapa chave para o apoio à manutenção da amamentação.

Visando estimular e instrumentalizar a rede básica de saúde para implantar um conjunto de procedimentos de promoção, proteção e apoio ao aleitamento materno nos serviços de pré-natal e de pediatria, foi lançada, pela Secretaria de Estado de Saúde do Rio de Janeiro (SESRJ) em 1999, de forma pioneira, a Iniciativa Unidade Básica Amiga da Amamentação (IUBAAM). Essa iniciativa foi fruto de uma demanda do Grupo Técnico Interinstitucional de Incentivo ao Aleitamento Materno, que, desde a segunda metade da década de 90, vinha capacitando não apenas equipes hospitalares, mas também equipes de assistência primária no manejo e apoio ao aleitamento materno (Resolução $n$. 837, de 30 de março de 1993. Diário Oficial do Estado do Rio de Janeiro 1993; 12 abr). Durante a década de 80, o Programa de Assistência Integral à Saúde da Mulher, Criança e Adolescente (PAISMCA) da SES-RJ, seguindo orientação do MS, desenvolvia ações de promoção do aleitamento materno no conjunto das ações básicas de saúde.

Este artigo analisa o processo de revisão e síntese de evidência da efetividade de uma política de saúde: estratégias e procedimentos de promoção, proteção e apoio ao aleitamento materno, e de verificação empírica de resultados da sua aplicação na rede básica de saúde do Estado do Rio de Janeiro, através do PAISMCA/ SES-RJ. Consideramos que a reflexão sobre as bases teóricas, a metodologia de avaliação e o impacto da IUBAAM na prevalência de aleitamento materno exclusivo nos primeiros seis meses de vida representam uma etapa necessária para a consolidação dessa Iniciativa em um programa de saúde estruturado. São colocados em perspectiva os pressupostos, as intervenções e os resultados da política de promoção, proteção e apoio ao aleitamento materno, desenvolvida em unidades básicas de saúde, e é destacada a contribuição dos depoimentos das gestantes e mães usuárias para a análise do desempenho dessas unidades.

\section{Metodologia}

A política de promoção, proteção e apoio ao aleitamento materno em curso no final da década de 90 e início da década seguinte em unidades básicas de saúde do Estado do Rio de Janeiro, Brasil, foi analisada dentro de um modelo lógico 11, de modo a apresentar os resultados da avaliação conduzida, explicitando os pressupostos, as atividades conduzidas e os resultados específicos esperados. O modelo lógico é uma representação simplificada da seqüência das ações e das relações entre os recursos aplicados, as atividades desenvolvidas e os benefícios atribuíveis. Sumarizando o conjunto de ações que compõem o programa é possível apreender com maior clareza suas vantagens e limitações.

A partir da verificação de que os "passos para o sucesso do aleitamento materno" preconizados por países que possuíam um programa de promoção à amamentação na atenção básica à saúde, como o Chile 12, Peru 13, Nicarágua 14, Argentina 15 e Reino Unido 16, não eram baseados em evidência científica, foi realizada uma revisão sistemática 17 à procura de intervenções conduzidas durante a fase pré-natal e/ou de acompanhamento do binômio mãe-filho que estendessem a duração do aleitamento materno. Nesta revisão, foram contemplados estudos experimentais ou quasi-experimentais 18, sendo utilizada a definição da OMS 8 de aleitamento materno exclusivo (leite materno e mais nada, com exceção de medicamentos).

Os procedimentos e estratégias que se mostraram efetivos na extensão da duração do aleitamento materno, identificados por esta revisão, foram organizados em "passos" (Dez Passos para o Sucesso da Amamentação. http:// www.aleitamento.com, acessado em 30/Abr/ 2005), e são a base da IUBAAM.

Partiu-se então para o desenvolvimento de um modelo de avaliação das unidades básicas de saúde nessa iniciativa, baseado na metodologia de avaliação da IHAC 19 e na trilogia Donabediana 20: estrutura-processo-resultado. Esse modelo foi descrito em detalhes em outra publicação 21 e será apresentado resumidamen- 
te aqui. Para a avaliação de estrutura, foram elaborados instrumentos de observação do serviço e questionários estruturados para a entrevista a profissionais de saúde, a fim de verificar sua capacitação para a prática dos "passos" da iniciativa. Para a avaliação de processo, foram elaborados questionários estruturados para entrevistar gestantes e mães, a fim de investigar se haviam recebido as informações, orientações e apoio relativos àqueles "passos". Esse questionário continha também duas perguntas que averiguavam se e por que essas mulheres estavam satisfeitas (ou insatisfeitas) com o apoio prestado pela unidade de saúde para amamentar. Outro indicador de resultado selecionado foi a prevalência de aleitamento materno exclusivo entre os bebês menores de seis meses assistidos por essas unidades.

A IUBAAM, preconizando a prática dos procedimentos e estratégias efetivos identificados na revisão sistemática, organizados em "Dez Passos para o Sucesso da Amamentação”, e estabelecendo uma metodologia de avaliação dessa prática pelas unidades básicas de saúde, foi lançada pela SES-RJ em 1999. Para a validação do instrumental de avaliação da IUBAAM, uma amostra proposital 22 de 24 unidades básicas de saúde de diferentes regiões da capital, cinturão metropolitano e interior do Estado do Rio de Janeiro foi submetida à avaliação quanto à prática dos "Dez Passos para o Sucesso da Amamentação”.

A avaliação da estrutura e de processo gerava escores globais (EG) que podiam variar de 1 (todos os passos cumpridos pela unidade) a 0 (infra-estrutura inadequada e nenhum procedimento realizado pela unidade). Com base nesses escores, os níveis de desempenho das unidades avaliadas foram classificados em "bom" (EG de 0,67 ou acima), "regular" (EG entre 0,66 e 0,34) e "fraco" (EG de 0,33 ou abaixo). A avaliação foi conduzida em cada unidade pela primeira autora deste artigo, na época coordenadora do Grupo Técnico Interinstitucional de Incentivo ao Aleitamento Materno/SES-RJ, e pelo coordenador de saúde materno-infantil do respectivo município, treinado enquanto avaliador da IUBAAM. Foram entrevistados pelos avaliadores 240 gestantes, 240 mães de bebês, os 24 diretores das unidades e 236 profissionais / pessoal de saúde de diversas categorias. Pelas auxiliares de enfermagem que pesavam os bebês, foi aplicado um formulário de coleta de dados junto às mães dos 2.458 bebês menores de seis meses atendidos por essas 24 unidades durante o mês em que cada unidade estava sendo avaliada.

O nível de satisfação das gestantes e mães com o apoio recebido da unidade básica para amamentar foi medido através de um "escore de satisfação" derivado das respostas de vinte mulheres entrevistadas em cada unidade ("sim" = 1; “mais ou menos" = 0,5 ; “não" =0), gerando valores que podiam variar de 0,0 a 100,0\%. Além disso, foi desenvolvida a análise compreensiva dos significados expressos pelas mulheres acerca do apoio recebido da unidade básica de saúde para amamentar, a fim de identificar oportunidades de melhora do serviço. A pergunta aberta "por quê?" (da satisfação ou insatisfação), da última etapa da entrevista com as gestantes e mães, deu margem a uma relação empática com as depoentes, e a fenomenologia 23 foi adotada como possibilidade metodológica para discutir e interpretar a vivência do apoio recebido, expressa nos depoimentos como significados. A investigação fenomenológica interroga os entes, neste estudo, as gestantes e mães usuárias da rede básica de saúde; questiona o ser, a instância fundante que caracteriza cada uma das mulheres usuárias como uma pessoa única e singular; e procura o sentido do ser, a dimensão subjetiva dessas mulheres que doam significados às ações assistenciais de promoção, proteção e apoio à amamentação que recebem da equipe de saúde. A abordagem qualitativa foi conduzida com a construção de cinco estruturas essenciais de significação, a partir das falas das mulheres.

\section{Resultados}

Os pressupostos, as intervenções e os resultados da política de promoção, proteção e apoio ao aleitamento materno preconizada para o pré-natal e pediatria das unidades básicas de saúde estão articulados no modelo lógico sumarizado na Tabela 1, cuja análise é apresentada a seguir. A duração inferior ao desejável do aleitamento materno exclusivo configura a situação-problema e foi caracterizada sucintamente através da prevalência de aleitamento materno exclusivo no Brasil de 35,6\%, em 1999, entre os bebês menores de quatro meses 4 . Desta forma, com a introdução precoce de outros líquidos e/ou alimentos no primeiro semestre de vida, grande número de lactentes são expostos ao risco de infecções e distúrbios de crescimento e desenvolvimento, particularmente em grupos sociais desfavorecidos. A IUBAAM tem como pressuposto que atividades de atenção pré-natal e de puericultura/pediatria constituem uma oportunidade valiosa para atuação dos serviços na promoção da saúde e na prevenção e solução de problemas que podem levar ao desmame precoce. Considerando o es- 
Modelo lógico de avaliação da política de promoção, proteção e apoio à amamentação preconizada para o pré-natal e pediatria de unidades básicas de saúde do Estado do Rio de Janeiro, Brasil.

\begin{tabular}{|c|c|c|c|c|c|c|}
\hline $\begin{array}{l}\text { Situação- } \\
\text { problema }\end{array}$ & Prioridades & $\begin{array}{l}\text { Recursos } \\
\text { investidos }\end{array}$ & Atividades & Participação & $\begin{array}{l}\text { Desfechos } \\
\text { de curto } \\
\text { prazo }\end{array}$ & $\begin{array}{l}\text { Desfechos } \\
\text { de médio } \\
\text { prazo }\end{array}$ \\
\hline $\begin{array}{l}\text { Desmame } \\
\text { precoce: } \\
\text { introdução } \\
\text { de outros } \\
\text { líquidos e } \\
\text { alimentos } \\
\text { antes dos } \\
\text { seis meses } \\
\text { de idade. }\end{array}$ & $\begin{array}{l}\text { Experiência } \\
\text { anterior com } \\
\text { dificuldades } \\
\text { no manejo } \\
\text { da ama- } \\
\text { mentação. } \\
\text { Pressões } \\
\text { familiares } \\
\text { e sociais. }\end{array}$ & $\begin{array}{l}\text { Equipe } \\
\text { materno- } \\
\text { infantil } \\
\text { treinada em } \\
\text { ações de } \\
\text { promoção, } \\
\text { proteção e } \\
\text { apoio ao } \\
\text { aleitamento } \\
\text { materno. }\end{array}$ & $\begin{array}{l}\text { Orientação } \\
\text { e apoio ao } \\
\text { aleitamento } \\
\text { materno } \\
\text { durante o } \\
\text { pré-natal nas } \\
\text { consultas, } \\
\text { grupos de } \\
\text { gestantes } \\
\text { e outros. }\end{array}$ & $\begin{array}{l}\text { Gestantes } \\
\text { (e seus } \\
\text { familiares) } \\
\text { durante o } \\
\text { acompa- } \\
\text { nhamento } \\
\text { pré-natal. }\end{array}$ & $\begin{array}{l}\text { Aquisição } \\
\text { de autocon- } \\
\text { fiança para } \\
\text { amamentar. } \\
\text { Satisfação } \\
\text { das gestantes } \\
\text { com a } \\
\text { orientação } \\
\text { e o apoio } \\
\text { recebidos. }\end{array}$ & $\begin{array}{l}\text { Extensão d } \\
\text { duração do } \\
\text { aleitamentc } \\
\text { materno } \\
\text { exclusivo. }\end{array}$ \\
\hline
\end{tabular}

\begin{tabular}{|c|c|c|c|c|c|c|}
\hline $\begin{array}{l}\text { Desmame } \\
\text { precoce: } \\
\text { introdução } \\
\text { de outros } \\
\text { líquidos e } \\
\text { alimentos } \\
\text { antes dos } \\
\text { seis meses } \\
\text { de idade. }\end{array}$ & $\begin{array}{l}\text { Dificuldades } \\
\text { no manejo } \\
\text { da ama- } \\
\text { mentação. } \\
\text { Pressões } \\
\text { familiares } \\
\text { e sociais. }\end{array}$ & $\begin{array}{l}\text { Equipe } \\
\text { materno- } \\
\text { infantil } \\
\text { treinada em } \\
\text { ações de } \\
\text { promoção, } \\
\text { proteção e } \\
\text { apoio ao } \\
\text { aleitamento } \\
\text { materno. }\end{array}$ & $\begin{array}{l}\text { Orientação } \\
\text { e apoio no } \\
\text { manejo } \\
\text { da ama- } \\
\text { mentação } \\
\text { para mães de } \\
\text { lactentes nas } \\
\text { consultas, } \\
\text { grupos de } \\
\text { mães e } \\
\text { outros. }\end{array}$ & $\begin{array}{l}\text { Mães de } \\
\text { lactentes } \\
\text { (e seus } \\
\text { familiares) } \\
\text { durante o } \\
\text { acompa- } \\
\text { nhamento } \\
\text { pediátrico/de } \\
\text { puericultura. }\end{array}$ & $\begin{array}{l}\text { Prevenção/ } \\
\text { solução de } \\
\text { dificuldades } \\
\text { das mães } \\
\text { com a ama- } \\
\text { mentação. } \\
\text { Satisfação } \\
\text { das mães } \\
\text { com a } \\
\text { orientação } \\
\text { e o apoio } \\
\text { recebidos. }\end{array}$ & $\begin{array}{l}\text { Extensão da } \\
\text { duração do } \\
\text { aleitamento } \\
\text { materno } \\
\text { exclusivo. }\end{array}$ \\
\hline
\end{tabular}

Desfechos
de longo
prazo
Redução
da morbi-
mortalidade
infantil.

$\begin{aligned} & \text { Pressupostos } \text { Fatores } \\ & \text { externos }\end{aligned}$

Efetividade Orientação de ações de e rotinas da promoção, maternidade. proteção e Trabalho apoio ao materno. aleitamento Falta de inframaterno no estrutura de pré-natal. apoio social. Impacto da amamentação na queda da morbi-mortalidade infantil.

Efetividade Orientação de ações de e rotinas da promoção, maternidade. proteção e Trabalho apoio ao materno. aleitamento Falta de inframaterno na estrutura de pediatria. apoio social. Impacto da amamentação na queda da morbi-mortalidade infantil. Alcance limitado da IHAC.

\section{Elementos \\ para} avaliação

\begin{tabular}{|c|c|c|c|c|c|c|c|}
\hline $\begin{array}{l}\text { Caracteriza- } \\
\text { ção das } \\
\text { principais } \\
\text { inseguranças } \\
\text { e dificuldades } \\
\text { das gestantes } \\
\text { e mães em } \\
\text { relação à } \\
\text { amamentação. }\end{array}$ & $\begin{array}{l}\text { Grau de } \\
\text { conhecimento } \\
\text { e habilidades } \\
\text { no manejo e } \\
\text { no apoio à } \\
\text { amamentação } \\
\text { da equipe } \\
\text { materno- } \\
\text { infantil. }\end{array}$ & $\begin{array}{l}\text { Atividades } \\
\text { realizadas de } \\
\text { orientação e } \\
\text { apoio ao } \\
\text { aleitamento } \\
\text { materno. }\end{array}$ & $\begin{array}{l}\text { Adesão das } \\
\text { gestantes e } \\
\text { mães às } \\
\text { atividades de } \\
\text { orientação e } \\
\text { apoio ao } \\
\text { aleitamento } \\
\text { materno. }\end{array}$ & $\begin{array}{l}\text { Grau de } \\
\text { satisfação } \\
\text { das gestantes } \\
\text { e mães com } \\
\text { a orientação } \\
\text { e apoio } \\
\text { recebidos } \\
\text { para } \\
\text { amamentar. }\end{array}$ & $\begin{array}{l}\text { Duração do } \\
\text { aleitamento } \\
\text { materno } \\
\text { exclusivo. }\end{array}$ & $\begin{array}{l}\text { Crescimento } \\
\text { e desenvol- } \\
\text { vimento } \\
\text { infantil. } \\
\text { Sobrevivên- } \\
\text { cia infantil. }\end{array}$ & $\begin{array}{l}\text { Relação dose- } \\
\text { resposta entre } \\
\text { as atividades } \\
\text { desenvolvidas } \\
\text { e os desfechos } \\
\text { ocorridos. }\end{array}$ \\
\hline
\end{tabular}

copo das ações básicas de saúde, a promoção, proteção e apoio ao aleitamento materno poderiam ser vistos como responsabilidade primordial das unidades primárias de saúde. Comporiam, assim, o conjunto de ações básicas de saúde que justificam a própria existência de uma rede primária de saúde.

A estruturação da IUBAAM visou explorar melhor o potencial representado pelo ambiente da atenção básica à saúde e pelas ações já implementadas na rede. As prioridades da IUBAAM estão baseadas em determinantes co- nhecidos do desmame precoce, como as dificuldades no manejo da amamentação relacionadas à fase da apojadura 24 e às crises lactacionais 25 , e como as pressões do contexto familiar e social. Esses determinantes são também considerados vulneráveis a atividades de promoção, proteção e apoio ao aleitamento materno em unidades básicas de saúde. A implementação da IUBAAM envolveu a otimização de recursos já existentes na maior parte das unidades básicas: capacidade instalada e profissionais de saúde com prática de assistência 
a gestantes e mães. O esforço adicional para a implementação da IUBAAM era relativamente pequeno, mas não trivial, considerando outras demandas feitas aos serviços de saúde. Implicava em treinamento específico de profissionais de saúde para que as ações fossem desenvolvidas de forma homogênea e consistente, utilizando um conhecimento com base científica.

As atividades da IUBAAM se basearam no conjunto de procedimentos efetivos identificados pela revisão sistemática: informar sobre as vantagens do aleitamento materno precoce, exclusivo, sob livre demanda e continuado e sobre como o leite materno é produzido; escutar as preocupações e dúvidas das mulheres com a amamentação e prestar ajuda no manejo; alertar quanto aos riscos do uso de mamadeiras e chupetas; e orientar quanto aos métodos de contracepção adequados. As estratégias com evidência empírica de efetividade na condução desses procedimentos foram os grupos de pré-natal, as visitas domiciliares, os grupos de mães e as sessões individuais conduzidas no pré e pós-natal, proporcionando apoio face a face à amamentação e envolvendo os familiares nesse apoio 17 .

As atividades de grupo de mães e de gestantes se baseiam na noção de que a oportunidade dessas mulheres compartilharem em grupo suas expectativas, experiências e vivências em relação à amamentação, combinada à orientação pelos profissionais de saúde, pode prevenir dificuldades e permite lidar com a ansiedade, inseguranças e eventuais problemas relacionados ao aleitamento materno. Desta forma, seriam neutralizados alguns dos obstáculos ao aleitamento materno exclusivo. $\mathrm{O}$ impacto da amamentação exclusiva sobre a saúde geral do lactente já estava bem documentado 26 .

Na avaliação realizada em 24 unidades básicas de saúde de nove municípios quanto à prática dos "Dez Passos para o Sucesso da Amamentação” da IUBAAM, 13 unidades apresentaram desempenho regular, e 11 apresentaram desempenho fraco. As características sócio-demográficas das mulheres desses dois blocos de desempenho foram semelhantes 27 .

Todos os procedimentos investigados foram mais praticados no bloco de unidades de desempenho regular do que no bloco de desempenho fraco, com exceção de um passo que estava sendo cumprido pelo conjunto de unidades avaliadas: nenhuma mulher entrevistada havia sido exposta à propaganda ou recebido doação de fórmulas infantis, mamadeiras ou bicos na unidade. A prevalência de aleitamento materno exclusivo encontrada na clientela de bebês menores de seis meses acompanha- dos pelas unidades básicas de saúde avaliadas foi baixa. Quase a metade $(47,9 \%)$ das mães já fornecia água, chá ou suco $(19,5 \%)$ ou outros alimentos $(28,3 \%)$ desde o primeiro mês de vida. A prevalência de aleitamento materno exclusivo foi maior no bloco de unidades de desempenho regular que no bloco de desempenho fraco $(38,6 \%$ e $23,6 \%$, respectivamente; $p<0,001)$, diferença esta que se apresentou consistentemente em todas as faixas etárias, e se acentuou no quinto e sexto meses de vida 27 .

O trabalho materno fora do lar pareceu afetar a prática da amamentação: a prevalência de aleitamento materno exclusivo foi o dobro $(34,7 \%)$ entre as mães que não trabalhavam fora em relação às mães que trabalhavam fora $(16,9 \%)$. Por outro lado, entre as mulheres que receberam ajuda para amamentar da maternidade, $34,0 \%$ amamentavam exclusivamente, contra $29,0 \%$ das mães que não receberam apoio do hospital. Esses fatores, no entanto, não pareceram interferir nos resultados do aleitamento materno entre os dois blocos avaliados, considerando a semelhança na proporção de mães dos blocos de desempenho regular e fraco que tiveram ajuda da maternidade para amamentar $(61,5 \%$ e $62,8 \%$, respectivamente; $\mathrm{p}=$ $0,55)$ e que trabalhava fora $(15,1 \%$ e $12,7 \%$, respectivamente; $\mathrm{p}=0,11) 27$.

Foi verificada a associação entre a medida de resultado "prevalência de aleitamento materno exclusivo entre bebês menores de seis meses" e a avaliação de estrutura e processo representada pelo Escore Global da unidade, sendo encontrada uma correlação moderada entre ambas (coeficiente de correlação linear de Pearson =0,648; $\mathrm{p}<0,01$ ) 27. Já a medida de resultado "satisfação das mulheres com o apoio recebido da unidade para amamentar" variou amplamente entre as unidades básicas, mostrando-se fortemente correlacionada com os Escores Globais (coeficiente de correlação linear de Pearson $=0,897 ; p<0,000$ ). No bloco de unidades de desempenho regular, foi observado o dobro da satisfação $(61,9 \%)$ encontrada no bloco de unidades de desempenho fraco $(31,4 \%) 21$.

A análise compreensiva dos depoimentos das gestantes e mães sobre as razões pelas quais as mesmas se sentiram (ou não) apoiadas para amamentar pela unidade de saúde levou ao seu agrupamento em cinco estruturas essenciais de significação: "nenhum apoio”, “apoio dúbio", "apoio como incentivo”, “apoio no manejo" e "apoio como parceria".

A estrutura de significação "nenhum apoio" expressa, em princípio, a percepção das mulheres de ausência de qualquer apoio dado pela unidade. Essa significação foi referida por 
$67,0 \%$ das gestantes e mães assistidas pelo bloco de unidades de desempenho fraco (BF) e por $18,0 \%$ daquelas acompanhadas pelo bloco de desempenho regular (BR). Estas falas exprimem sentimentos de abandono, de assistência fragmentada à mulher, de auto-culpabilização da mulher pela falta de apoio ou pelo insucesso com a amamentação, e de uso de material informativo ao invés do diálogo. Incluiu falas eloqüentes, como:

- Abandono: "não chegam perto, não conversam, não explicam...", "por que eu continuo com as minhas dúvidas e não sei como fazer pra dar mais tempo só no peito e não largar".

- Assistência fragmentada à mulher: "sobre estas conversas comigo não. Só pediu pra vir aqui medir a pressão", "não estão falando sobre isso. Só medem a barriga e escutam o coração do neném".

- Auto-culpabilização: "ela quase não falou de peito comigo, porque eu quase não tinha mais leite".

- Uso de material informativo ao invés do diálogo: "não falaram nada contra nem a favor, só o papelzinho que eu ganhei".

Ao serem perguntadas por que se sentiam (ou não) apoiadas para amamentar pela unidade, a resposta de $6,0 \%$ das mulheres $(7,0 \%$ do $\mathrm{BF}$ vs. 5,0\% do BR) foi categorizada como "apoio dúbio", abrangendo tanto a dificuldade de caracterização do apoio, quanto a referência a uma mensagem conflitante ou contrária à amamentação.

- Dificuldade de caracterização: "não sei explicar...".

- Mensagem conflitante: "toda semana a doutora mandava insistir, mas se ele começar a tomar nojo, dar a mamadeira pra não perder peso". - Mensagem contrária: "falaram pra tirar do peito com 6 meses, eu queria que meu peito desse mais leite pra ela”, "porque eu, quando vi, já estava com o peito rachado e com mastite, $e$ mandou parar e passar pomada".

Para 20,0\% das mulheres assistidas pelo BF e $38,0 \%$ daquelas acompanhadas pelo $\mathrm{BR}$, o apoio à amamentação é referido como "incentivo" que se configura como motivação ou persuasão. Em geral, o incentivo foi referido de forma positiva, mas algumas falas sinalizam a sua insuficiência para o apoio efetivo à amamentação:

- Motivação: "falam: ó, que bom que ela está só no peito!", “eles falam sobre o leite materno, mas quero saber mais um pouco, como devo fazer?".

- Persuasão: "dizem que é bom, que a criança não fica doente", "a doutora falou preu insistir, mas não adiantou”.

A percepção de que a unidade tinha dado apoio à amamentação foi referida como o rece- bimento de "apoio no manejo" do aleitamento materno, que se configura em orientação sobre como amamentar, como lidar com intercorrências da amamentação, e até sobre como gerenciar o cotidiano, por apenas $4,0 \%$ das mulheres assistidas pelo BF e por $23,0 \%$ daquelas acompanhadas pelo BR, como nos depoimentos abaixo: - Como amamentar: "eles explicam bem como dar mamá à criança”.

- Como lidar com intercorrências: "Eu tava com o peito rachado e tirava na bomba. Ensinaram que o neném sugando a ferida fecha”, "eles sempre falam pra deixar ela sugar que o leite vem".

- Como gerenciar o cotidiano: "aconselharam a não tirar do peito, eu ia tirar o peito porque ia trabalhar e aconselharam a levar ele pro trabalho, e a patroa aceitou".

A estrutura de significação "apoio como parceria" abrangeu referências ao diálogo, à facilidade de acesso, à ajuda, ao aumento da autoconfiança, e à relação de afeto, tendo sido referida por uma proporção ainda pequena de mulheres: $2,0 \%$ das gestantes e mães entrevistadas no bloco de desempenho fraco e $16,0 \%$ daquelas entrevistadas no bloco de desempenho regular:

- Diálogo: "eles sempre conversam comigo".

- Acesso: "eles explica e atende direitinho, é perto e pode vir sem hora marcada", "na reunião apoiou, já vim em três reunião”.

- Ajuda: "está ajudando bastante coisa, na primeira eu tive problema, o peito rachou", "eu sempre que chego aqui encontro socorro".

- Autoconfiança: "eu tive firmeza de acreditar que ele podia se alimentar só no peito".

- Afeto: "a equipe daqui é amiga".

\section{Discussão}

Em que pese o avanço alcançado na recuperação da prática da amamentação ao longo das últimas décadas no Brasil, a prevalência de aleitamento materno exclusivo nos primeiros seis meses de vida ainda está muito aquém da desejável, contribuindo para os níveis de desnutrição e de morbi-mortalidade infantis ainda altos em nosso país.

A revisão sistemática desenvolvida sugere que a perspectiva de redução do desmame precoce a partir da assistência primária à saúde engendrou uma grande diversidade de ações básicas desenvolvidas em diferentes contextos dos cinco continentes com o objetivo de aumentar a duração da amamentação. Dessa forma, o conjunto de passos da IUBAAM propostos a partir desta revisão sistemática tem uma 
abrangência global e não apenas local. No entanto, ressaltamos que as características diferenciadas da rede primária de saúde existentes nas várias partes do mundo precisam ser mais bem investigadas, e os instrumentos de avaliação desenvolvidos necessitam ser testados em campo em outros contextos sociais e de assistência à saúde.

A avaliação das unidades básicas de saúde foi conduzida por examinadores externos à unidade, porém internos ao programa de promoção ao aleitamento materno. Um dos aspectos que contribuiu para tornar esta avaliação das unidades básicas de saúde extremamente produtiva foi o envolvimento dos coordenadores municipais da assistência materno-infantil, e de profissionais e pessoal de saúde das unidades, na proposta de avaliação trazida pelo Grupo Técnico Interinstitucional de Incentivo ao Aletamento Materno/SES-RJ. Entre as vantagens do envolvimento de avaliadores internos estão a capacidade de captar e enfocar as questões de maior relevância para o programa e de contextualizar seus resultados. O modelo de avaliação propiciou o reconhecimento imediato das oportunidades de melhora nas ações do programa e permitiu resgatar o princípio da imputabilidade (accountability), ou seja, de "prestar contas" do trabalho realizado. A subjetividade e limitação da capacidade crítica, uma das desvantagens dos avaliadores internos, foram minimizadas pela objetividade dos instrumentos de avaliação e pelo treinamento e uniformização de condutas durante a avaliação, que teve a participação de profissionais externos ao programa e ao próprio sistema de saúde.

Foi interessante observar que o fator determinante da prevalência de aleitamento materno exclusivo encontrada na clientela das unidades básicas de saúde avaliadas não pareceu ser o nível de complexidade dessas unidades 27 , nem o contexto rural ou urbano nos quais elas se inseriam. Fatores como idade, paridade, experiência prévia com amamentação e escolaridade maternas apresentaram uma distribuição semelhante entre os dois blocos de unidades. Confundidores potenciais, como o trabalho materno e a ajuda recebida do hospital para amamentar, não pareceram explicar a associação entre as práticas de apoio à amamentação e a duração do aleitamento materno exclusivo.

A prática de procedimentos e estratégias efetivas, identificados através da revisão sistemática, mostrou ser o fator preponderante para as maiores proporções de aleitamento materno exclusivo observadas em todas as faixas etárias, entre os bebês menores de seis meses acompanhados pelas unidades de desempe- nho regular. Os índices encontrados nessa fase inicial de implantação da IUBAAM no Estado, no entanto, ainda se situaram muito aquém dos desejados, já que, mesmo nas unidades de desempenho regular, quase $40,0 \%$ dos bebês no primeiro mês de vida já estavam recebendo outros líquidos ou alimentos, e no sexto mês de vida, essa proporção ultrapassou os $80,0 \% 27$.

$\mathrm{O}$ indicador de resultado "grau de satisfação das mães com o apoio recebido das unidades para amamentar", obtido de um desfecho imediato utilizado de forma inovadora neste estudo, pareceu menos influenciado por fatores controlados e não controlados que o indicador prevalência de aleitamento materno, referido a um desfecho de médio prazo tradicionalmente utilizado (Tabela 1). Este estudo sugere que as gestantes e mães são capazes de perceber de forma acurada se o serviço está ou não as apoiando a amamentar e não têm receio de expressar sua opinião para avaliadores externos à unidade. Nesse sentido, esse indicador mostrou-se mais útil do que costumam ser, em geral, os indicadores de satisfação do usuário.

O método utilizado de avaliação das práticas das unidades básicas de saúde na promoção, proteção e apoio ao aleitamento materno foi validado no trabalho de campo. A validade de conteúdo 28 dos instrumentos e das medidas por ele geradas está baseada nos procedimentos e estratégias identificadas como efetivas em estender o aleitamento materno pela revisão sistemática 17 . A validade de constructo 28 foi demonstrada pela associação encontrada entre os resultados da avaliação de processo e estrutura e da avaliação de resultado. Ao enfatizar os componentes de processo, a avaliação identificou direta e objetivamente as oportunidades de melhora das ações do programa.

A análise qualitativa deu voz às mulheres. Deu também sentido e significado à avaliação quantitativa, contribuindo para a compreensão da forma como as intervenções do programa podem aumentar a duração do aleitamento materno exclusivo. A eloqüência dos depoimentos das gestantes e das mães nos remete à urgência de assegurar que a rede básica de saúde se constitua em um espaço onde a mulher seja vista na sua integralidade e efetivamente apoiada para amamentar. É necessário tanto o domínio de técnicas de manejo da amamentação pela equipe de saúde, quanto a construção de uma postura de diálogo, no lugar da atual conduta basicamente prescritiva, para que essa rede possa atuar de forma efetiva na promoção, proteção e apoio ao aleitamento materno. 


\section{Conclusões e desdobramentos}

A investigação em serviços de saúde acrescenta desafios àqueles próprios à pesquisa científica. Observar e documentar ações de saúde no cotidiano dos serviços para gerar dados confiáveis sobre a efetividade de programas implica em opções metodológicas que privilegiam componentes pragmáticos e concede grau de controle do investigador sobre seu objeto de pesquisa. Enfatiza-se a aplicabilidade dos resultados em cenários reais, em oposição à ênfase do ambiente acadêmico no desvendamento dos mecanismos pelos quais os resultados são obtidos, e a relativa facilidade de entendimento e interpretação dos resultados pela direção e pelos profissionais de saúde das unidades. Tratase também de minimizar a interferência da observação e coleta de dados sobre o cenário em que se realizam as ações de saúde, valorizando a validade externa, ou seja, a possibilidade de generalizar os resultados obtidos.

O lançamento da IUBAAM no Estado do Rio de Janeiro em 1999 foi realizado com apoio de representantes da área materno-infantil de Secretarias Municipais de Saúde, entidades de classe e representantes de organizações não-governamentais. O Grupo Técnico Interinstitucional de Aleitamento Materno, responsável pelo planejamento, assessoria na execução e avaliação das ações de promoção, proteção e apoio ao aleitamento materno no Estado tem, desde então, apoiado às instâncias regionais e municipais de saúde na implantação da IUBAAM.

O MS passou a contribuir para essa Iniciativa a partir de 2001, reunindo mensalmente uma equipe de consultores que, ao longo de dois anos, desenvolveu um material de capacitação de equipes de saúde na IUBAAM, constituído de um manual técnico e de um conjunto de apresentações 29 . O curso teórico-prático correspondente, de 24 horas de carga horária, tem sido aplicado por Secretarias Municipais de Saúde das várias regiões do Rio de Janeiro, e recentemente outros Estados têm também desenvolvido cursos de capacitação de multiplicadores e de avaliadores de unidades básicas de saúde.

Atualmente, mais de 2/3 dos municípios do Rio de Janeiro dispõem de equipe de multiplicadores da IUBAAM, e 32 unidades já foram credenciadas na iniciativa no Estado. Em um destes municípios, Piraí, no interior do Estado, onde toda a rede básica de saúde - constituída por dez unidades - recebeu o título de "Amiga da Amamentação", a prevalência de aleitamento materno exclusivo nos bebês menores de seis meses praticamente triplicou num período de cinco anos, passando de 13,6\% em 1998 para 39,3\% em 2003 30,31.

Em contraste, em outros municípios que ainda não estavam envolvidos com a Iniciativa, não se observou variação substancial na prevalência da amamentação exclusiva entre os anos de 1998 e 2003: no município de Santo Antônio de Pádua, foram encontrados índices de 11,5\% e 12,9\%, respectivamente; e em Quissamã, $13,7 \%$ em ambos 30,31 .

Em municípios que atuavam na implementação da IUBAAM, mas que só dispunham de uma unidade básica credenciada, foi observado um aumento - embora menos expressivo na prevalência de aleitamento materno exclusivo entre os anos de 1998 e 2003, como em Volta Redonda ( $17,1 \%$ e $34,1 \%$, respectivamente), Nova Friburgo $(24,2 \%$ e $38,2 \%$, respectivamente) e Teresópolis $(34,2 \%$ e $49,9 \%$, respectivamente) 30,31. Esses achados sugerem, portanto, um "efeito dose-resposta", a ser confirmado em novas pesquisas.

Os dados apresentados neste estudo parecem indicar que a capacitação de profissionais de saúde, seu crescente envolvimento enquanto equipe e a implantação de normas e rotinas adequadas são fatores que podem levar a um melhor aproveitamento do potencial já existente nas atuais condições da rede básica de saúde, gerando um bom desempenho da mesma na promoção, proteção e apoio à amamentação.

Considerando a evidência científica já disponível quanto a estratégias e procedimentos aplicados na assistência primária à gestante $\mathrm{e}$ ao binômio mãe-filho com efetividade na extensão da duração do aleitamento materno, bem como a simplicidade e acurácia do método de avaliação desenvolvido, podemos concluir que a implementação de uma Iniciativa Global de Promoção, Proteção e Apoio à Amamentação na Atenção Primária à Saúde poderá contribuir para o aumento da prevalência do aleitamento materno exclusivo no Brasil e em outros países. Embora esteja fora do escopo deste trabalho, parece importante considerar que a IUBAAM poderá melhorar a relação custo-efetividade das ações de promoção do aleitamento materno, tendo em vista o impacto potencial dessas ações, sua articulação com outras atividades de atenção básica e a possibilidade de otimizar o uso de recursos já existentes. 


\section{Resumo}

Este artigo avalia uma política de promoção, proteção e apoio ao aleitamento materno desenvolvida em unidades básicas de saúde do Estado do Rio de Janeiro, Brasil, analisando seus pressupostos, intervenções e resultados com base em um modelo lógico. Através de uma revisão sistemática, foram identificados procedimentos e estratégias efetivas na extensão da duração do aleitamento materno, os quais compuseram os "Dez Passos" da "Iniciativa Unidade Básica Amiga da Amamentação", lançada no Estado em 1999. Uma metodologia de avaliação correspondente foi desenvolvida e utilizada para verificar o desempenho de 24 unidades básicas de saúde de diferentes partes do Estado. Foi verificada uma associação direta da prática desses passos com a prevalência de aleitamento materno exclusivo e com a satisfação da clientela. Uma análise dos significados atribuídos pelas gestantes e mães acerca do apoio recebido da unidade básica de saúde para amamentar identificou cinco estruturas de significação: "nenhum apoio", "apoio dúbio", "incentivo", "manejo" e "parceria". O modelo de avaliação propiciou o reconhecimento imediato das oportunidades de melhora nas ações do programa para a reversão dos baixos índices de aleitamento materno exclusivo.

Aleitamento Materno; Cuidados Primários de Saúde; Promoção da Saúde

\section{Colaboradores}

M. I. C. Oliveira participou de todas as etapas, da coleta de dados à análise e redação final do artigo. L. A B. Camacho participou da análise dos dados quantitativos e da redação final do artigo. I. E. O. Souza participou da análise dos dados qualitativos e colaborou na redação do artigo.

\section{Agradecimentos}

Os autores gostariam de agradecer a Alison E. Tedstone, da London School of Hygiene and Tropical Medicine, pela supervisão à realização da revisão sistemática, aos coordenadores materno-infantis, pela atuação na avaliação das unidades básicas de saúde, e também à Secretaria de Estado de Saúde do Rio de Janeiro, à CAPES e UNICEF-New York pelo apoio financeiro e logístico a este trabalho.

\section{Referências}

1. Instituto Brasileiro de Geografia e Estatística. Estudo Nacional de Despesa Familiar (ENDEF). Rio de Janeiro: Instituto Brasileiro de Geografia e Estatística; 1975.

2. Leão MM, Coitinho DC, Recine E, Costa LAL, Lacerda AJ. O perfil do aleitamento materno no Brasil. In: Instituto Brasileiro de Geografia e Estatística/Fundo das Nações Unidas para a Infância, organizadores. Perfil estatístico de crianças e mães no Brasil. Aspectos de saúde e nutrição de crianças no Brasil. Rio de Janeiro: Instituto Brasileiro de Geografia e Estatística; 1992. p. 97-109.

3. Sociedade Civil Bem-estar Familiar no Brasil. Pesquisa Nacional sobre Demografia e Saúde, 1996. Rio de Janeiro: Sociedade Civil Bem-estar Familiar no Brasil; 1997.

4. Ministério da Saúde. Pesquisa de prevalência do aleitamento materno nas capitais e no Distrito Federal. Brasília: Ministério da Saúde; 2001.

5. Sociedade Civil Bem-estar Familiar no Brasil. Pesquisa Nacional sobre Demografia e Saúde, 1986. Rio de Janeiro: Sociedade Civil Bem-estar Familiar no Brasil; 1987.

6. Rea MF. Reflexões sobre a amamentação no Brasil: de como passamos a 10 meses de duração. Cad Saúde Pública 2003; 19 Suppl 1:37-45.

7. World Health Organization. The optimal duration of exclusive breastfeeding: results of a WHO systematic review. Geneva: World Health Organization; 2001. (Note for the Press 7).

8. World Health Organization. Indicators for assessing breast-feeding practices. Geneva: World Health Organization; 1992.

9. Saadeh R, Akré J. Ten steps to successful breastfeeding: a summary of the rationale and scientific evidence. Birth 1996; 23:154-60.

10. Neifert M, Gray J, Gary N, Camp B. Factors influencing breast-feeding among adolescents. J Adolesc Health Care 1988; 9:470-3.

11. Rossi PH, Lipsey MW, Freeman HE. Evaluation: a systematic approach. $7^{\text {th }}$ Ed. Thousand Oaks: Sage Publications; 2004.

12. Ministerio de Salud de la República de Chile, Comisión Nacional de Lactancia Materna. Criterios de evaluación de consultorios que apoyan la iniciativa conjunta OMS-UNICEF Hospitales Amigos. Santiago de Chile: Ministerio de Salud de la República de Chile; 1995.

13. Giga VTS, Sanez NC. Centros y puestos promotores de la alimentación infantil: once pasos hacia una adecuada alimentación infantil. Lima: Centro de Promoción y Estudios em Nutrición; 1996.

14. Ministry of Education of Nicaragua. Eleven steps to PHC for successful breastfeeding. In: United Nations Children's Fund, editor. Baby-friendly hospital initiative. Case studies and progress report. New York: United Nations Children's Fund; 1999. p. 17-25.

15. Vallone F, Mercer R. Programa materno infantil, Ministerio de Salud. 10 acciones del primer nivel de atención en apoyo de la lactancia materna. Buenos Aires: Ministério de la Salud; 1997.

16. The United Nations Children's Fund UK Baby Friendly Initiative. A seven point plan for the pro- 
tection, promotion and support of breastfeeding in community health care settings. London: The United Nations Children's Fund UK Baby Friendly Initiative; 1998.

17. Oliveira MIC, Camacho LAB, Tedstone AE. Extending breastfeeding duration through primary care: a systematic review of prenatal and postnatal interventions. J Hum Lact 2001; 17:326-43.

18. Rothman KJ. Modern epidemiology. Boston: Little, Brown and Company; 1986.

19. United Nations Children's Fund/World Health Organization/Wellstart International. Baby-friendly hospital initiative: external assessors' manual. Geneva: United Nations Children's Fund/World Health Organization; 1992.

20. Donabedian A. Explorations in quality assessment and monitoring. v. I: The definition of quality and approaches to its assessment. Ann Arbor: Health Administration Press; 1980.

21. Oliveira MIC, Camacho LAB, Tedstone AE. A method for the evaluation of primary care unit's practice in the promotion, protection, and support of breastfeeding: results from the State of Rio de Janeiro, Brazil. J Hum Lact 2003; 19:365-73.

22. Worthen BR, Sanders JR, Fitzpatrick JL. Program evaluation: alternative approaches and practical guidelines. 2nd Ed. New York: Longman; 1997.

23. Heidegger M. Ser e tempo. 3a Ed. Petrópolis: Editora Vozes; 1989.

24. Chapman D, Pérez-Escamilla R. Identification of risk factors for delayed onset of lactation. J Am Diet Assoc 1999; 99:450-4.
25. Verronen P. Breast feeding: reasons for giving up and transient lactational crises. Acta Paediatr Scand 1982; 71:447-50.

26. Akre J. Infant feeding. The physiological basis. Bull World Health Organ 1989; 67 Suppl:1-108.

27. Oliveira MIC, Camacho LAB. Impacto das unidades básicas de saúde na duração do aleitamento materno exclusivo. Rev Bras Epidemiol 2002; 5:41-51.

28. Carmines EG, Zeller RA. Reliability and validity assessment. Beverly Hills/London: Sage Publications; 1979.

29. Oliveira MIC, Teruya KM, Souza IEO, Alencar SMSM, Santos EKA. Iniciativa unidade básica amiga da amamentação: curso de 24 horas para multiplicadores [CD-ROM]. Rio de Janeiro: Programa de Assistência Integral à Saúde da Mulher, Criança e Adolescente, Secretaria de Estado de Saúde do Rio de Janeiro; 2003.

30. Secretaria de Estado de Saúde do Rio de Janeiro. Prática alimentares no primeiro ano de vida. Rio de Janeiro: Secretaria de Estado de Saúde do Rio de Janeiro; 2002. (Nutrivida: Boletim Informativo da Área Técnica de Alimentação e Nutrição, ano II, n. 1).

31. Secretaria de Estado de Saúde do Rio de Janeiro. Prática alimentares no primeiro ano de vida. Rio de Janeiro: Secretaria de Estado de Saúde do Rio de Janeiro; 2003. (Nutrivida: Boletim Informativo da Área Técnica de Alimentação e Nutrição, ano III, n. 1).

Recebido em 13/Dez/2004

Versão final reapresentada em 04/Mai/2005 Aprovado em 30/Mai/2005 